\title{
Reduced Expression of TCR Zeta Is Involved in the Abnormal Production of Cytokines by Peripheral T Cells of Patients with Systemic Lupus Erythematosus
}

\author{
Keiko Yoshimoto, ${ }^{1,2}$ Yumiko Setoyama, ${ }^{1}$ Kensei Tsuzaka, ${ }^{1,3}$ \\ Tohru Abe, ${ }^{1}$ and Tsutomu Takeuchi ${ }^{1,2}$ \\ ${ }^{1}$ Division of Rheumatology and Clinical Immunology, Saitama Medical Center, Saitama Medical University, \\ Kawagoe, Saitama 330-8550, Japan \\ ${ }^{2}$ Division of Rheumatology and Clinical Immunology, Department of Internal Medicine, \\ Keio University School of Medicine, Shinjuku-ku, Tokyo 160-8582, Japan \\ ${ }^{3}$ Division of Rheumatology, Department of Internal Medicine, Tokyo Dental College, Ichikawa General Hospital, \\ Ichikawa, Chiba 272-8513, Japan
}

Correspondence should be addressed to Keiko Yoshimoto, keikoy@a8.keio.jp

Received 28 March 2010; Revised 13 July 2010; Accepted 20 August 2010

Academic Editor: Brian Poole

Copyright (C) 2010 Keiko Yoshimoto et al. This is an open access article distributed under the Creative Commons Attribution License, which permits unrestricted use, distribution, and reproduction in any medium, provided the original work is properly cited.

\begin{abstract}
Accumulating evidence suggests that dysfunction of T cells underlies the pathogenesis of systemic lupus erythematosus (SLE). We revealed that SLE T cells produced an abnormally excessive amount of IFN- $\gamma$ in vitro upon stimulation through TCR, and the expression level of TCR zeta was significantly reduced. The production of IFN- $\gamma$ by SLE T cells was negatively correlated with the expression level of TCR zeta. This correlation was abolished when the cells were stimulated with TPA and ionomycin, which bypass TCR and introduce signals directly into the cells, but the production of IFN- $\gamma$ by SLE T cells remained abnormally elevated. Taken together, these data suggest that regulatory mechanisms not only for the expression of TCR zeta but also for the production of IFN- $\gamma$ were impaired in SLE T cells. These impairments may be responsible for the aberrant responses of SLE T cells and partly involved in the development of SLE.
\end{abstract}

\section{Introduction}

Systemic lupus erythematosus (SLE) is an autoimmune disease characterized by the production of a variety of autoantibodies, which may readily form immune complexes causing such disorders as lupus nephritis [1-3]. Several lines of evidence have suggested that dysfunction of $\mathrm{T}$ cells underlies the pathogenesis of the disease although malfunction of B cells may be directly responsible for the abnormal production of autoantibodies. For example, it has been reported that IFN- $\alpha$ and IFN- $\gamma$ produced by T cells are implicated in the pathogenesis of SLE [4-7]. In addition, serum levels of inflammatory cytokines including IFN- $\gamma$ and IL-6 were abnormally elevated in SLE patients [4, 7, 8]. Moreover, T cells from SLE patients showed excessive production of cytokines in response to various stimuli in vitro [9-15]. All of these data collectively imply possible involvement of $\mathrm{T}$ cells in the pathogenesis of SLE.

We have previously reported that the expression of TCR zeta is suppressed in peripheral $\mathrm{T}$ cells of patients afflicted with SLE, and the expression level of TCR zeta is correlated with some symptoms of the disease, such as butterfly rash and vasculitis $[16,17]$. Other investigators have also observed reduced expression of TCR zeta in SLE T cells [18-20]. It may be noteworthy that several SLE patients have a deletion in exon 7 of the TCR zeta gene, which spans the GTP/GDP binding site and a part of the third ITAM domain [21]. Taken together, it is postulated that the suppression of the expression of TCR zeta and/or functional abnormalities of TCR zeta in SLE T cells cause abnormal responses of T 
cells which in turn lead to aberrations of B cells. In the present study, we provide data suggesting that both the signal transduction cascade via TCR and the regulatory mechanism of the expression of IFN- $\gamma$ are impaired in T cells of SLE patients.

\section{Materials and Methods}

2.1. Monoclonal Antibodies and Recombinant Human Cytokines. Antibodies against CD3 (HIT3a), IL-2 (MQ1$17 \mathrm{H} 12$ and B33-2), and IFN- $\gamma$ (B27 and 4S.B3) were purchased from BD Biosciences Pharmingen (San Diego, USA.). An anti-TCR zeta antibody (TIA-2) was purchased from Santa Cruz (Santa Cruz, USA.). Recombinant human IL-2 and IFN- $\gamma$ as the standards for ELISA were also purchased from BD Biosciences Pharmingen.

2.2. Subjects. Venous blood samples were collected from Japanese SLE patients ( $n=20$, female, age 19-49 (average age: 36.2)) who met the revised ACR classification and healthy individuals ( $n=7$, female, age 22-41 (average age: 34.4)) under informed consent. All the patients diagnosed were clinically inactive when the samples were collected. This study was approved by the Ethics Committee at Saitama Medical University.

2.3. Cell Culture. Peripheral T cells were enriched by mixing whole venous blood with RosetteSep T cell Enrichment Cocktail (StemCell Technologies, Vancouver, Canada) and separating cells with Ficoll-Hypaque (GE Healthcare, Buckinghamshire, UK) density gradient centrifugation as described previously in [22]. FACS analysis revealed that the purity of the T cells was $>90 \%$.

2.4. Analysis of the Expression Level of TCR Zeta. The expression level of TCR zeta in SLE T cells was analyzed with a combination of immunoprecipitation and immunoblotting as described previously in [16]. In brief, peripheral T cells were suspended in a lysis buffer, and the lysate was mixed with an anti-TCR zeta antibody, TIA-2. After centrifugation, proteins in the immunoprecipitate were separated through SDSpolyacrylamide gel and transferred onto a PVDF membrane filter (Millipore, Bedford, USA.) which was subsequently probed with the same antibody. Bands corresponding to TCR zeta were quantified, and the results were normalized against the control.

2.5. Cell Culture and Quantification of Cytokines. Peripheral $\mathrm{T}$ cells $\left(5 \times 10^{5}\right)$ prepared from SLE patients and healthy individuals were cultured in RPMI1640 medium supplemented with 10\% FBS (JRH Biosciences, Lenexa, USA.) and $5 \times 10^{-5} \mathrm{M}$ of 2 -mercaptoethanol (Sigma-Aldrich, St. Louis, USA.). For stimulation of the $\mathrm{T}$ cells through TCR, the cells were seeded in 24-well plates previously coated with $10 \mu \mathrm{g} / \mathrm{mL}$ of an anti-CD3 antibody and cultured at $7 \% \mathrm{CO}_{2}$ and $37^{\circ} \mathrm{C}$. For "polyclonal stimulation", T cells were cultured in 24-well plates under the same conditions in the presence of $1 \mu \mathrm{g} / \mathrm{mL}$ of TPA (Sigma-Aldrich, St. Louis, USA.) and
$0.1 \mu \mathrm{g} / \mathrm{mL}$ of ionomycin (Sigma-Aldrich, St. Louis, USA.). The amounts of IL- 2 and IFN- $\gamma$ in the culture supernatants were measured by ELISA. The data were normalized against those for control T cells.

2.6. RT-PCR Analysis. Total RNAs were extracted from cells using total RNA Extracting Kit (Sigma-Aldrich, St. Louis, USA.). Twenty ng of total RNAs were subjected to reverse transcription using ReverTra Dash (Toyobo, Tokyo, Japan). For RT-PCR analysis, transcripts for IFN- $\gamma$ and GAPDH (glyceraldehyde 3-phosphate dehydrogenase) were amplified using AdvanTaq DNA Polymerase (Clontech, Palo Alto, USA.). The following primer set was synthesized for IFN- $\gamma$ : $5^{\prime}$-atgaaatatacaagttstatcttggcttt (forward) and $5^{\prime}$-gatgctcttcgacctcgaaacagcat (reverse). A primer set for GAPDH was purchased from Toyobo (Tokyo, Japan). The reaction conditions were as follows: $30 \mathrm{~s}$ at $94^{\circ} \mathrm{C}$ for denaturation and 1.5 minutes at $72^{\circ} \mathrm{C}$ for annealing and primer extension ( 35 cycles). The resultant DNA fragments were separated through a $1.5 \%$ agarose gel and stained with cyber green.

\section{Results}

3.1. Cytokine Production by T Cells Stimulated through TCR. In order to investigate possible functional abnormalities of SLE T cells, we examined cellular responses against stimuli through TCR. To this end, T cells prepared from SLE patients ("SLE T cells") and healthy individuals ("control T cells") were cultured in 24-well plates previously coated with an anti-CD3 antibody, HIT3a, which introduces signals into T cells through TCR and induces the production of IFN- $\gamma$ and IL-2 by the cells. Based on our previous experiments, the cells were cultured for 2 or 4 days for the maximal production of IFN- $\gamma$ or IL-2, respectively. Our preliminary experiments revealed that the stimulatory effect of the anti-CD3 antibody in combination with an anti-CD28 antibody on peripheral $\mathrm{T}$ cells was indistinguishable from the sole effect of the anti-CD3 antibody in the production of IL- 2 and IFN- $\gamma$. Therefore, we used only anti-CD3 antibody as a stimulus to simplify the experiments.

The baseline productions of IFN- $\gamma$ and IL- 2 by both control and SLE T cells were below the detection limit without stimulation (data not shown). Stimulation of the cells with the anti-CD3 antibody induced the production of IFN- $\gamma$. SLE $\mathrm{T}$ cells produced a significantly higher amount of IFN- $\gamma$ than control T cells under the employed conditions (Figure 1). An irrelevant antibody did not induce the production of IL-2 nor of IFN- $\gamma$ (data not shown). These results indicate that SLE T cells were "hyperactivated" by the stimulation in the production of IFN- $\gamma$. On the other hand, there was no significant difference between SLE and control $\mathrm{T}$ cells in the production of IL-2 although the cells produced substantial amount of IL-2 upon stimulation (Figure 1).

3.2. Gene Expression of IFN- $\gamma$ in T Cells. The abnormal responses of SLE T cells were further analyzed by RTPCR. Although the stimulation of the control T cells with 


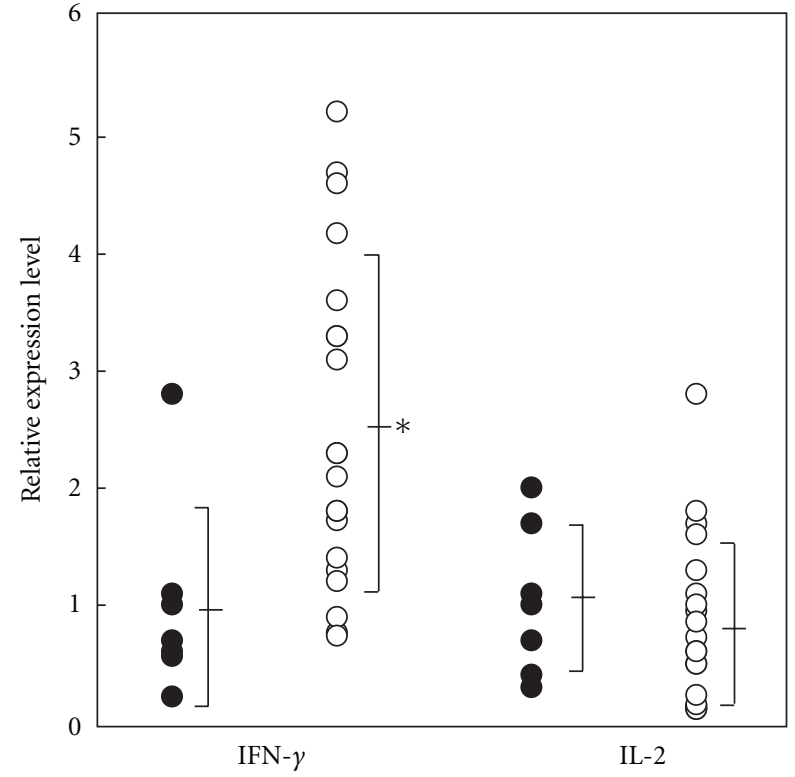

FIgURE 1: Production of IFN- $\gamma$ and IL-2 by T cells upon stimulation with an anti-CD3 antibody. Peripheral T cells $\left(5 \times 10^{5}\right)$ from SLE patients ( $n=20$; open circles) and healthy individuals ( $n=7$; filled circles) were cultured in 24-well plates previously coated with $10 \mu \mathrm{g} / \mathrm{mL}$ of an anti-CD3 antibody for 2 (IFN- $\gamma$ ) or 4 (IL-2) days. The amounts of IFN- $\gamma$ and IL- 2 in the supernatants were measured by ELISA, and the data were normalized against those for the control. Data represent mean \pm SD. ${ }^{*} P<.05$.
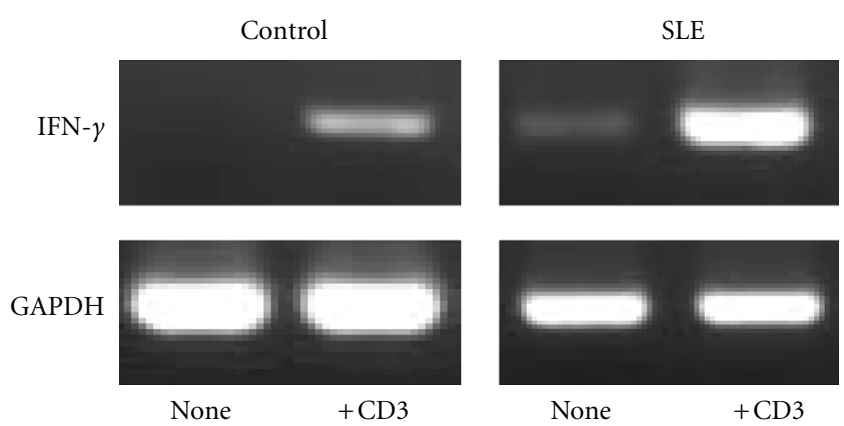

Figure 2: RT-PCR analysis of gene expression of IFN- $\gamma$ upon stimulation with an anti-CD3 antibody. Control T cells (Control) and SLE T cells (SLE) were cultured in the presence $(+C D 3)$ or absence (None) of stimulation. Twenty ng of total RNAs extracted from the cells were subjected to RT-PCR for IFN- $\gamma$ and GAPDH. The resultant DNA fragments were separated through a $1.5 \%$ agarose gel and stained with cyber green.

the anti-CD3 antibody only slightly induced the expression of the IFN- $\gamma$ gene (Figure 2; Control), a remarkable increase in the expression was detected when SLE T cells were stimulated with the antibody (Figure 2; SLE). These data, along with the results in Figure 1, suggest that the induction of the expression of the IFN- $\gamma$ gene per se was responsible for the excessive production of IFN- $\gamma$ in stimulated SLE $\mathrm{T}$ cells.
3.3. Relationship between the Expression Level of TCR Zeta and IFN- $\gamma$ Production. Our previous experiments revealed that the expression of TCR zeta was suppressed in the substantial number of SLE patients $[16,17]$. In addition, the expression level of TCR zeta was correlated with several clinical manifestations of SLE [16]. These data prompted us to investigate the relationship between the expression level of TCR zeta and the production of IFN- $\gamma$ in T cells.

The average of the relative expression level of TCR zeta of SLE T cells from all of the patients thus far examined was significantly lower than that of control T cells (Figure 3(a); $1.00 \pm 0.28$ for the control versus $0.33 \pm 0.26$ for SLE). We noticed that the expression level of TCR zeta in each individual patient showed large variance ranging from 0.002 to 0.720 . Therefore, we analyzed the relationship between the expression level of TCR zeta and the production of IFN- $\gamma$ or IL-2. Notably, the production of IFN- $\gamma$ by SLE T cells was negatively correlated with the expression level of TCR zeta when the cells were stimulated through TCR (Figure 3(b)). The correlation was statistically significant $(r=-0.492, P<$ $.05)$. On the other hand, the production of IL-2 by SLE $\mathrm{T}$ cells had a strong positive correlation $(r=0.738, P<$ .001 ) with the expression level of TCR zeta (Figure 3(c)). No significant correlation was detected among control $\mathrm{T}$ cells $(r=0.289, P=.530)$. These results suggest that TCR zeta plays an important role in the signal transduction through TCR and that the excessive production of IFN- $\gamma$ by SLE T cells is attributed to the reduced expression of TCR zeta.

3.4. Cytokine Production by T Cells upon Polyclonal Stimulation. There are several possibilities that account for the abnormal production of IFN- $\gamma$ by SLE T cells: one is that the signal transduction cascade through TCR is aberrant so that signals are exaggerated by TCR complex which results in the induction of the excessive production of IFN $-\gamma$. However, another possibility that the regulatory mechanisms for the production of IFN- $\gamma$ are impaired in SLE T cells may not be ruled out. To test this hypothesis, we employed TPA and ionomycin, $\mathrm{a} \mathrm{Ca}^{2+}$ ionophore, for "polyclonal stimulation" of T cells, which bypass TCR and directly activate the expression of the IFN $-\gamma$ gene.

SLE T cells produced $5.4 \pm 4.6$ times as much IFN- $\gamma$ as control T cells upon polyclonal stimulation (Figure 4) while the ratio was $2.5 \pm 1.4$ when the cells were stimulated through TCR (Figure 1). In addition, no significant correlation was observed between the expression level of TCR zeta and the production of IFN- $\gamma$ in SLE T cells $(r=-0.206, P=.383)$. These data suggest that the regulatory mechanism for the production of IFN- $\gamma$ was impaired in SLE T cells. On the other hand, polyclonal stimulation did not cause significant difference between control and SLE T cells in the production of IL-2, suggesting that the machinery for the production of IL-2 was not severely impaired in SLE T cells (Figure 4).

\section{Discussion}

Several lines of evidence have revealed a crucial role of zeta, a subunit of TCR, in the signaltransduction through 


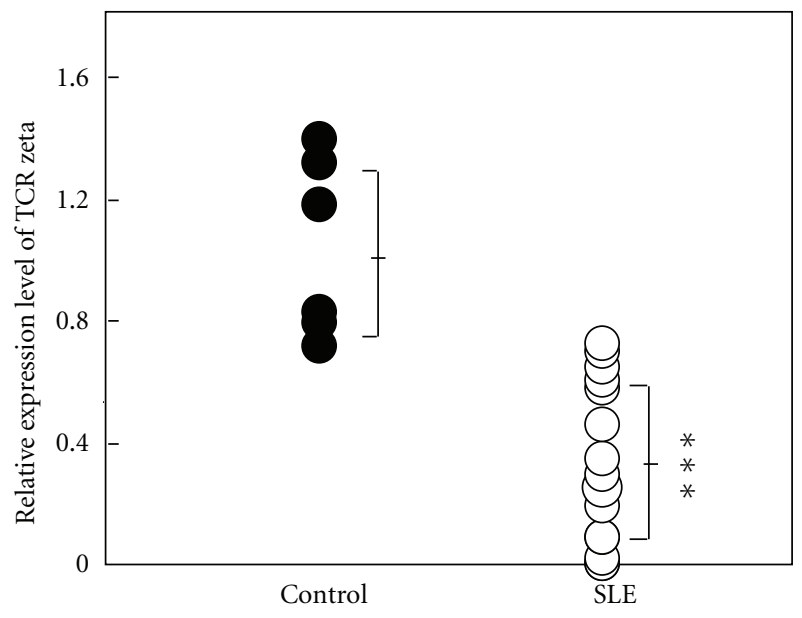

(a)

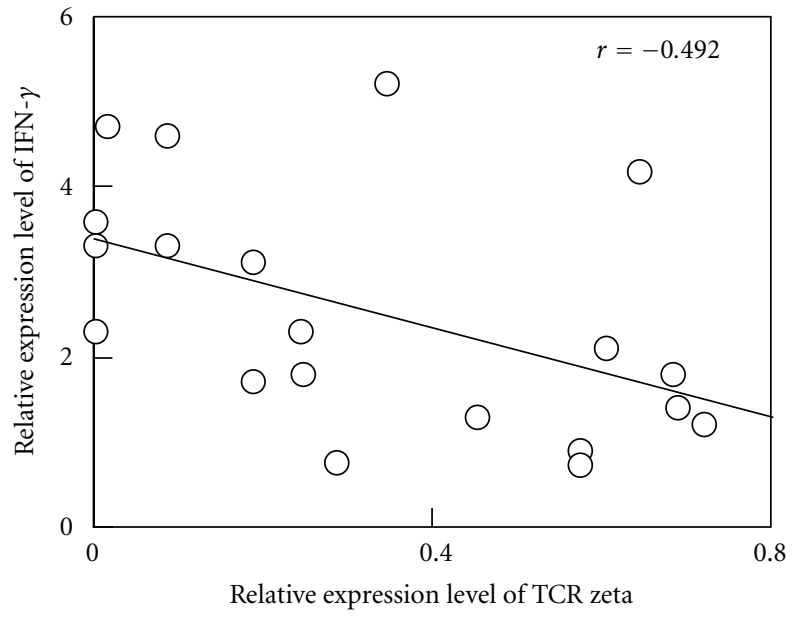

(b)

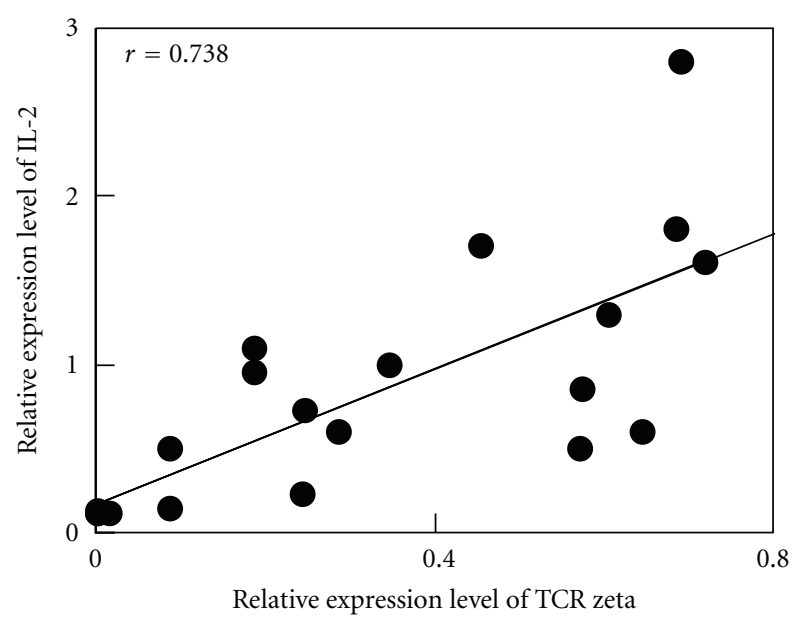

(c)

FIGURE 3: Correlation between the expression levels of TCR zeta and cytokines. The amounts of TCR zeta expressed in control ( $n=7)$ and SLE $(n=20)$ T cells were estimated as described in Materials and Methods. The amount of TCR zeta in T cells from individual patient was normalized against the average of the control. (a) The average expression level of TCR zeta of SLE T cells was compared with that of control T cells. Data represent mean \pm SD. ${ }^{* * *} P<.001$. (b, c) Scattergrams were depicted between the expression level of TCR zeta and the expression level of IFN- $\gamma$ (b) or IL-2 (c).

TCR [23-25]. In addition, not a few investigators including our group have reported that the expression of TCR zeta is reduced in SLE T cells [16-20]. In the present study, we attempted to elucidate the possible mechanism for how the reduced expression of TCR zeta underlies the development of SLE. To address this issue, we investigated in vitro responses of SLE T cells against various stimuli. As a response of T cells, we especially focused on the production of IFN $-\gamma$ by the cells since IFN- $\gamma$ induces the differentiation of B cells which play a pivotal role in the pathogenesis of SLE by producing autoantibodies [26]. In order to confirm the stimulation of $\mathrm{T}$ cells, production of IL-2 by the cells was examined simultaneously.

Stimulation of control and SLE T cells in vitro with an anti-CD3 antibody, an inducer of signal transduction through TCR, elicited the production of IFN $-\gamma$ by the cells. The production of IFN- $\gamma$ was abnormally elevated in SLE
$\mathrm{T}$ cells as compared with control $\mathrm{T}$ cells (Figure 1), as a consequence of the excessive expression of the IFN- $\gamma$ gene (Figure 2). It should be noted that the production of IFN- $\gamma$ showed significantly negative correlation with the expression level of TCR zeta (Figure 3(b)), suggesting that the reduced expression of TCR zeta is at least partly responsible for the abnormal responses of SLE T cells. Our previous findings indicated that several clinical manifestations of SLE patients were correlated with the expression level of TCR zeta though no statistically significant difference was observed between the expression level of TCR zeta and disease activity [16].

These data are consistent with the findings that (1) mutations in the zeta gene are relevant to the onset of the disease in some patients [21, 27-29] and (2) a mutation in ITAM of TCR zeta causes autoimmunity in mice, and T cells from such mice produced more IFN- $\gamma$ than wild-type T cells [30]. It is known that the function of TCR is negatively 


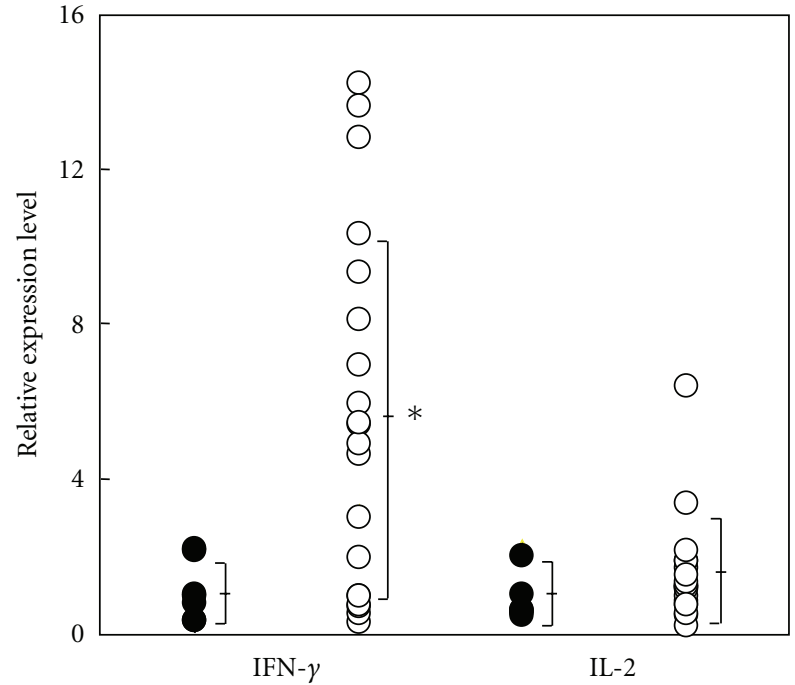

FIGURe 4: Production of IFN- $\gamma$ and IL-2 by T cells upon stimulation with TPA and ionomycin. Control T cells (filled circles) and SLE T cells (open circles) were cultured according to the method described in the legend of Figure 1 except that $1 \mu \mathrm{g} / \mathrm{mL}$ of TPA and $0.1 \mu \mathrm{g} / \mathrm{mL}$ of ionomycin were used as stimuli. The amounts of IFN- $\gamma$ and IL2 in the supernatants were measured by ELISA, and the data were normalized against those for the control. Data represent mean \pm SD. ${ }^{*} P<.05$.

regulated by CTLA-4, which downregulates activated TCR through association with phosphorylated TCR zeta [31, 32]. Taken together, we speculate that SLE T cells are devoid of negative regulation of the expression of IFN- $\gamma$ because CTLA-4 is unable to downregulate activated SLE T cells due to the reduced expression of TCR zeta. A recent report indicates that the function of CTLA- 4 is abnormal in SLE $\mathrm{T}$ cells [33]. Therefore, functional aberration of CTLA-4 and quantitative abnormality of TCR zeta may synergistically induce abnormal responses of SLE T cells.

We then carried out several experiments to reveal whether or not the reduced expression of TCR zeta is solely responsible for the aberration in the production of IFN- $\gamma$. For this purpose, SLE and control T cells were stimulated with TPA and ionomycin ("polyclonal stimulation") which bypass TCR and activate the signal transduction cascade distal to TCR. If the machinery for the production of IFN- $\gamma$ had been intact in SLE T cells, the responses of the cells would have been similar to those of control $\mathrm{T}$ cells upon stimulation. The results revealed no significant correlation between the production of IFN- $\gamma$ and the expression level of TCR zeta $(r=-0.206, P=.383)$, probably because polyclonal stimulation which bypasses TCR was used as a stimulus. The fact that SLE T cells still produced an abnormally excessive amount of IFN- $\gamma$ in spite of polyclonal stimulation (Figure 4) raised the possibility that the regulatory mechanism for the production of IFN- $\gamma$ was also impaired in SLE T cells.

In conclusion, our data in the present study suggest that the regulatory mechanisms not only for the expression of TCR zeta, but also for the production of IFN- $\gamma$, were impaired in SLE T cells, and these abnormalities may be involved in the development of SLE. We hope our results as well as the findings by others on the abnormalities of SLE $\mathrm{T}$ cells open a new field for therapeutic possibilities to treat SLE.

\section{Abbreviations}

$\begin{array}{ll}\text { RT-PCR: } & \text { Reverse transcription-polymerase chain } \\ & \text { reaction } \\ \text { SLE: } & \text { Systemic lupus erythematosus } \\ \text { TCR: } & \text { T cell receptor. }\end{array}$

\section{Acknowledgments}

This paper was supported in part by a grant-in-aid for Scientific Research from the Ministry of Education, Culture, Sports, Science and Technology of Japan (no. 20591193). The authors thank Dr. Makoto Yoshimoto for his help in preparing this paper.

\section{References}

[1] D. T. Boumpas, H. A. Austin III, B. J. Fessler, J. E. Balow, J. H. Klippel, and M. D. Lockshin, "Systemic lupus erythematosus: emerging concepts-part 1: renal, neuropsychiatric, cardiovascular, pulmonary, and hematologic disease," Annals of Internal Medicine, vol. 122, no. 12, pp. 940-950, 1995.

[2] D. T. Boumpas, B. J. Fessler, H. A. Austin III, J. E. Balow, J. H. Klippel, and M. D. Lockshin, "Systemic lupus erythematosus: emerging concepts_-part 2: dermatologic and joint disease, the antiphospholipid antibody syndrome, pregnancy and hormonal therapy, morbidity and mortality, and pathogenesis," Annals of Internal Medicine, vol. 123, no. 1, pp. 42-53, 1995.

[3] J. A. Mills, "Systemic lupus erythematosus," New England Journal of Medicine, vol. 330, no. 26, pp. 1871-1879, 1994.

[4] M. Al-Janadi, S. Al-Balla, A. Al-Dalaan, and S. Raziuddin, "Cytokine profile in systemic lupus erythematosus, rheumatoid arthritis, and other rheumatic diseases," Journal of Clinical Immunology, vol. 13, no. 1, pp. 58-67, 1993.

[5] E. C. Baechler, F. M. Batliwalla, G. Karypis et al., "Interferoninducible gene expression signature in peripheral blood cells of patients with severe lupus," Proceedings of the National Academy of Sciences of the United States of America, vol. 100, no. 5, pp. 2610-2615, 2003.

[6] K. P. Machold and J. S. Smolen, "Interferon- $\gamma$ induced exacerbation of systemic lupus erythematosus," Journal of Rheumatology, vol. 17, no. 6, pp. 831-832, 1990.

[7] T. Karonitsch, E. Feierl, C. W. Steiner et al., "Activation of the interferon- $\gamma$ signaling pathway in systemic lupus erythematosus peripheral blood mononuclear cells," Arthritis and Rheumatism, vol. 60, no. 5, pp. 1463-1471, 2009.

[8] S. Mellor-Pita, M. J. Citores, R. Castejon et al., "Monocytes and $\mathrm{T}$ lymphocytes contribute to a predominance of interleukin 6 and interleukin 10 in systemic lupus erythematosus," Cytometry Part B, vol. 76, no. 4, pp. 261-270, 2009.

[9] V. Brinkmann, T. Geiger, S. Alkan, and C. H. Heusser, "Interferon $\alpha$ increases the frequency of interferon $\gamma$-producing human CD4+ T cells," Journal of Experimental Medicine, vol. 178, no. 5, pp. 1655-1663, 1993.

[10] P. L. Cohen, "T- and B-cell abnormalities in systemic lupus," Journal of Investigative Dermatology, vol. 100, no. 1, pp. 69S72S, 1993. 
[11] D. M. Chang, W. L. Su, and S. J. Chu, "The expression and significance of intracellular $\mathrm{T}$ helper cytokines in systemic lupus erythematosus," Immunological Investigations, vol. 31, no. 1, pp. 1-12, 2002.

[12] S. Sierakowski, E. J. Kucharz, R. W. Lightfoot, and J. S. Goodwin, "Impaired T-cell activation in patients with systemic lupus erythematosus," Journal of Clinical Immunology, vol. 9, no. 6, pp. 469-476, 1989.

[13] M. Kawamoto, M. Harigai, M. Hara et al., "Expression and function of inducible co-stimulator in patients with systemic lupus erythematosus: possible involvement in excessive interferon- $\gamma$ and anti-double-stranded DNA antibody production," Arthritis Research and Therapy, vol. 8, no. 3, article no. R62, 2006.

[14] M. Linker-Israeli, A. C. Bakke, F. P. Quismorio Jr., and D. A. Horwitz, "Correction of interleukin-2 production in patients with systemic lupus erythematosus by removal of spontaneously activated suppressor cells," Journal of Clinical Investigation, vol. 75, no. 2, pp. 762-768, 1985.

[15] B. L. Kotzin, "Systemic lupus erythematosus," Cell, vol. 85, no. 3, pp. 303-306, 1996.

[16] M. Pang, Y. Setoyama, K. Tsuzaka et al., "Defective expression and tyrosine phosphorylation of the $\mathrm{T}$ cell receptor zeta chain in peripheral blood $\mathrm{T}$ cells from systemic lupus erythematosus patients," Clinical and Experimental Immunology, vol. 129, no. 1, pp. 160-168, 2002.

[17] K. Tsuzaka, T. Takeuchi, N. Onoda, M. Pang, and A. Tohru, "Mutations in T cell receptor $\zeta$ chain mRNA of peripheral T cells from systemic lupus erythematosus patients," Journal of Autoimmunity, vol. 11, no. 5, pp. 381-385, 1998.

[18] L. Berg, J. Rönnelid, L. Klareskog, and A. Bucht, "Downregulation of the $\mathrm{T}$ cell receptor $\mathrm{CD} 3 \xi$ chain in rheumatoid arthritis (RA) and its influence on T cell responsiveness," Clinical and Experimental Immunology, vol. 120, no. 1, pp. 174-182, 2000.

[19] L. Krymskaya, W.-H. Lee, L. Zhong, and C.-P. Liu, "Polarized development of memory cell-like IFN- $\gamma$-producing cells in the absence of TCR $\zeta$-chain," Journal of Immunology, vol. 174, no. 3, pp. 1188-1195, 2005.

[20] M. P. Nambiar, S. Krishnan, V. G. Warke, and G. C. Tsokos, "TCR zeta-chain abnormalities in human systemic lupus erythematosus," Methods in Molecular Medicine, vol. 102, pp. 49-72, 2004.

[21] T. Takeuchi, K. Tsuzaka, M. Pang, K. Amano, J. Koide, and T. Abe, "TCR $\zeta$ chain lacking exon 7 in two patients with systemic lupus erythematosus," International Immunology, vol. 10, no. 7, pp. 911-921, 1998.

[22] K. Yoshimoto, Y. Takahashi, M. Ogasawara et al., "Aberrant expression of BAFF in T cells of systemic lupus erythematosus, which is recapitulated by a human T cell line, Loucy," International Immunology, vol. 18, no. 7, pp. 1189-1196, 2006.

[23] A. M. Weissman, M. Baniyash, D. Hou, E. Samelson, W. H. Burgess, and R. D. Klausner, "Molecular cloning of the zeta chain of the T cell antigen receptor," Science, vol. 239, no. 4843, pp. 1018-1021, 1988.

[24] S. J. Frank, B. B. Niklinska, D. G. Orloff, M. Mercep, J. D. Ashwell, and R. D. Klausner, "Structural mutations of the T cell receptor $\zeta$ chain and its role in T cell activation," Science, vol. 249, no. 4965, pp. 174-177, 1990.

[25] B. A. Irving and A. Weiss, "The cytoplasmic domain of the $\mathrm{T}$ cell receptor $\zeta$ chain is sufficient to couple to receptorassociated signal transduction pathways," Cell, vol. 64, no. 5, pp. 891-901, 1991.
[26] M. Funauchi, H. Sugishima, M. Minoda, and A. Horiuchi, "Effect of interferon- $\gamma$ on B lymphocytes of patients with systemic lupus erythematosus," Journal of Rheumatology, vol. 18, no. 3, pp. 368-372, 1991.

[27] K. Tsuzaka, Y. Setoyama, K. Yoshimoto et al., "A splice variant of the TCR $\zeta$ mRNA lacking exon 7 leads to the down-regulation of TCR $\zeta$, the TCR/CD3 complex, and IL2 production in systemic lupus erythematosus T cells," Journal of Immunology, vol. 174, no. 6, pp. 3518-3525, 2005.

[28] K. Tsuzaka, I. Fukuhara, Y. Setoyama et al., “TCR $\zeta$ mRNA with an alternatively spliced 3 - -untranslated region detected in systemic lupus erythematosus patients leads to the downregulation of TCR $\zeta$ and TCR/CD3 complex," Journal of Immunology, vol. 171, no. 5, pp. 2496-2503, 2003.

[29] K. Tsuzaka, Y. Itami, C. Kumazawa et al., "Conservative sequences in $3^{\prime}$ UTR of TCR $\zeta$ mRNA regulate TCR $\zeta$ in SLE T cells," Biochemical and Biophysical Research Communications, vol. 367, no. 2, pp. 311-317, 2008.

[30] J. Holst, H. Wang, K. D. Eder et al., "Scalable signaling mediated by $\mathrm{T}$ cell antigen receptor-CD3 ITAMs ensures effective negative selection and prevents autoimmunity," Nature Immunology, vol. 9, no. 6, pp. 658-666, 2008.

[31] S. Chikuma, J. B. Imboden, and J. A. Bluestone, "Negative regulation of $\mathrm{T}$ cell receptor-lipid raft interaction by cytotoxic T lymphocyte-associated antigen 4," Journal of Experimental Medicine, vol. 197, no. 1, pp. 129-135, 2003.

[32] K.-M. Lee, E. Chuang, M. Griffin et al., "Molecular basis of T cell inactivation by CTLA-4," Science, vol. 282, no. 5397, pp. 2263-2266, 1998.

[33] E. C. Jury, F. Flores-Borja, H. S. Kalsi et al., "Abnormal CTLA-4 function in T cells from patients with systemic lupus erythematosus," European Journal of Immunology, vol. 40, no. 2, pp. 569-578, 2010. 


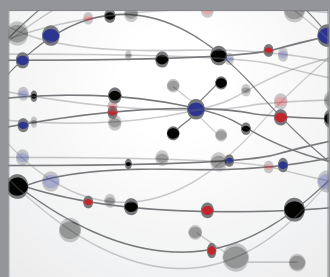

The Scientific World Journal
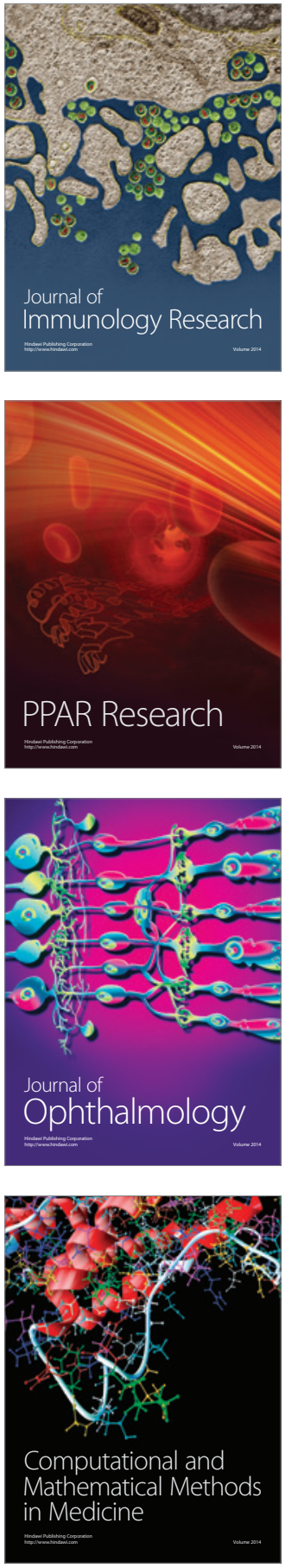

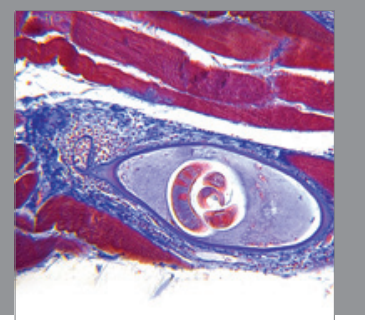

Gastroenterology

Research and Practice
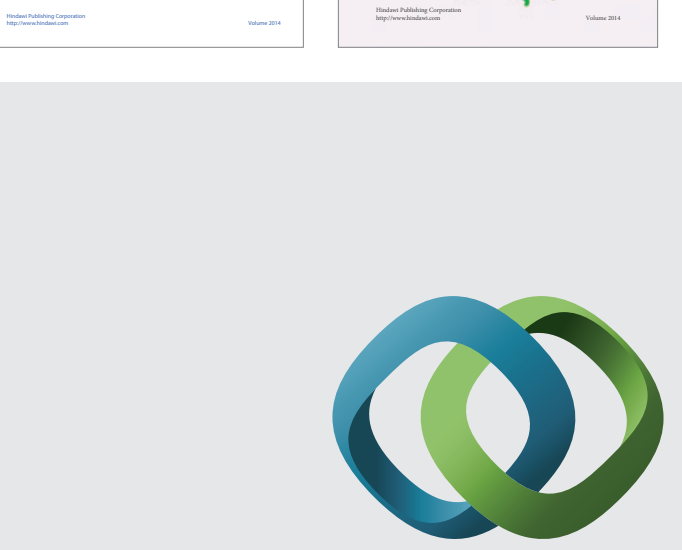

\section{Hindawi}

Submit your manuscripts at

http://www.hindawi.com
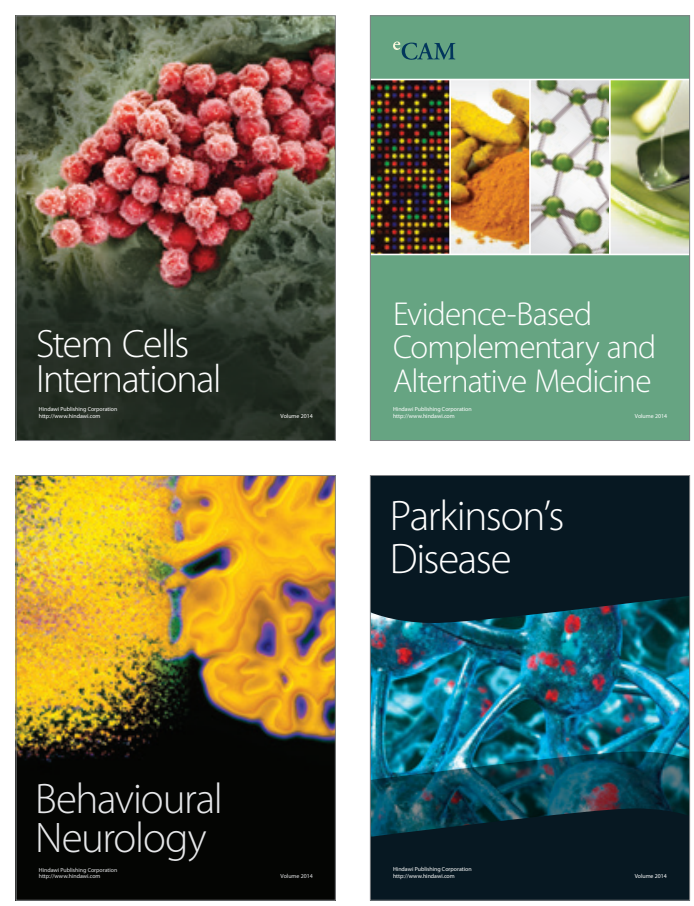

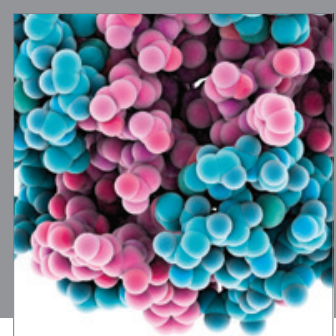

Journal of
Diabetes Research

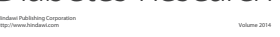

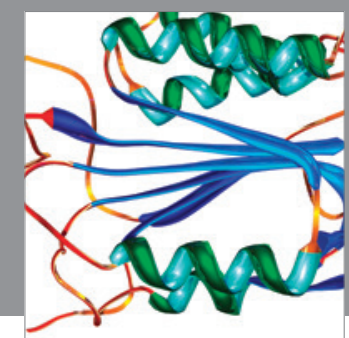

Disease Markers
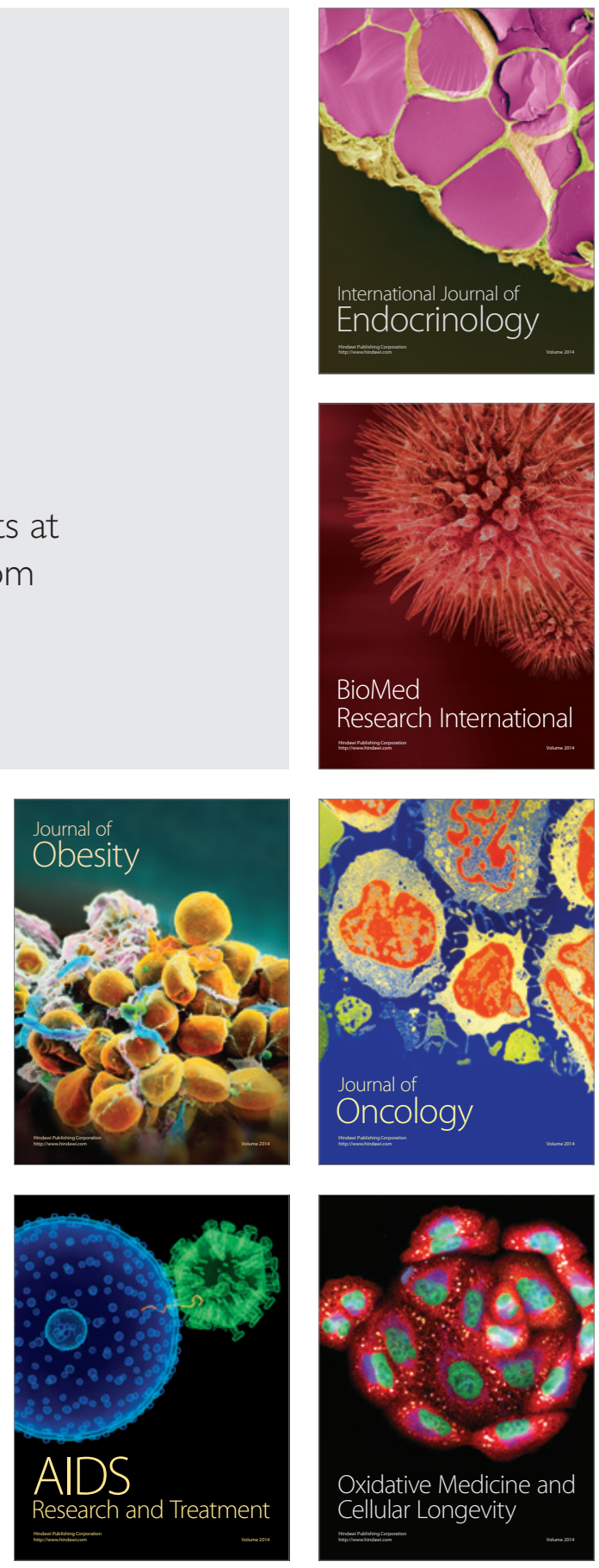